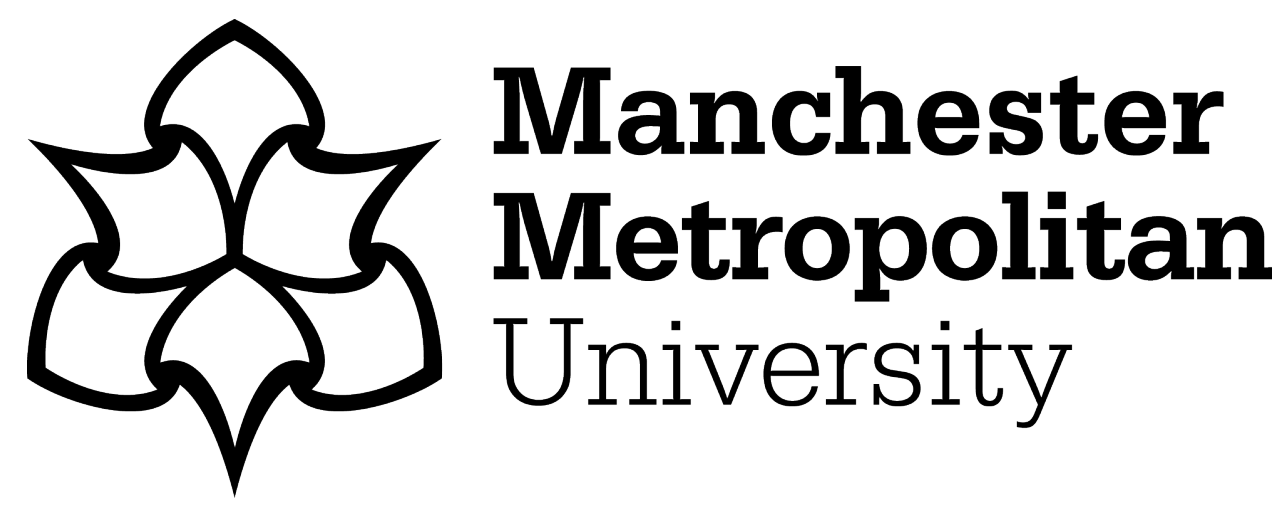

Dao, Phung ORCID logoORCID: https://orcid.org/0000-0002-8612-5589 and Sato, Masatoshi (2021) Exploring fluctuations in the relationship between learners' positive emotional engagement and their interactional behaviours. Language Teaching Research, 25 (6). pp. 972-994. ISSN 1362-1688

Downloaded from: https://e-space.mmu.ac.uk/628323/

Version: Accepted Version

Publisher: SAGE Publications

DOI: https://doi.org/10.1177/13621688211044238

Please cite the published version 
Dao, P. \& Sato, M. (2021, in press). Exploring fluctuations in the relationship between learners'1 positive emotional engagement and their interactional behaviours. Language Teaching Research, accepted on 17 August 2021

Exploring fluctuations in the relationship between learners' positive emotional engagement and their interactional behaviours

Phung Dao, Manchester Metropolitan University, UK

$\&$ Masatoshi Sato, Universidad Andres Bello, Chile

Contact informaton:

Phung Dao (corresponding author)

Department of Languages, Information and Communications

Manchester Metropolitan University, UK

Email:p.dao@mmu.ac.uk

\section{Masatoshi Sato}

Department of English, Faculty of Education

Universidad Andres Bello, Chile

Email: masatoshi.sato@unab.cl

\section{Acknowledgments:}

This work was supported by the Comisión Nacional de Investigación Científica y Tecnológica (CONICYT: the Ministry of Education of Chile) under the Fondo National de Desarrollo Científico y Tecnólogico (FONDECYT: 1181533), as well as the PIA (CIE160009) received from the CONICYT, awarded to the second author. 
Dao, P. \& Sato, M. (2021, in press). Exploring fluctuations in the relationship between learners 2 positive emotional engagement and their interactional behaviours. Language Teaching Research, accepted on 17 August 2021 
Dao, P. \& Sato, M. (2021, in press). Exploring fluctuations in the relationship between learners 3 positive emotional engagement and their interactional behaviours. Language Teaching Research, accepted on 17 August 2021

\begin{abstract}
This study investigated the nature of learners' positive emotional engagement during a taskbased interaction and its relationship with their interactional behaviours. Vietnamese EFL learners $(N=74)$ performed a communicative task in dyads in 15 minutes. Their positive emotional engagement was gauged using an Experience Sampling Method via a questionnaire that the participants completed after every five-minute interval of the interaction, capturing three timepoints of learners' emotional engagement. Learners' cognitive and social interactional behaviours were examined in light of the amount of second language production (words and turns), language-related episodes (LREs), and the degree of collaboration. Results showed that learners' positive emotional engagement fluctuated over the course of a 15-minute interaction. Also, learners' levels of positive emotional engagement were positively correlated with the amount of L2 production and the degree of collaboration, but these relationships varied across the three intervals. No relationship was observed between learners' emotional engagement and LREs. The results indicate that although learners' positive emotional engagement may not be linked with their attention to form, relationships exist between learners' positive emotional engagement and their language production, as well as their social relationships. These relationships can be, however, subject to change over the course of a short interaction.
\end{abstract} Keywords: emotional engagement, language production, collaboration, task-based interaction, LREs 
Dao, P. \& Sato, M. (2021, in press). Exploring fluctuations in the relationship between learners'4 positive emotional engagement and their interactional behaviours. Language Teaching Research, accepted on 17 August 2021

\section{Introduction}

Given their critical role in task performance (Lambert, 2017; Mercer, 2019; see also Hiver et al., 2021a, b) and positive impact on second language (L2) learning such as lexical recall (Lambert et al., 2021; see also Fredricks et al., 2019; Reschly \& Christenson, 2012), L2 learners' emotions have been a subject of investigation in recent L2 research. This research has investigated emotions either in relation to other constructs, such as motivation and willingness to communicate (see Dewaele, 2019; Dörnyei \& Ryan, 2015), or as a subcomponent of a broader latent variable_-learner engagement (see Dao, 2019; Dao \& McDonough, 2018; Hiver et al., 2021a). While early L2 research primarily focused on negative emotions, such as L2 anxiety and unwillingness to communicate (see Horwitz, 2010; MacIntyre, 2017; Teimouri et al., 2019), more recent L2 research has focused on positive emotions, such as foreign language enjoyment in the classroom (Dewaele \& Dewaele, 2017; Dewaele \& MacIntyre, 2014, 2016), enjoyment and happiness in directed motivational currents (Ibrahim, 2016), and flow (Czimmermann \& Piniel, 2016). This body of research follows the current trend that emphasizes the dynamic nature of positive emotions which may constantly fluctuate, rather than being individuals' stable traits (see Boudreau et al., 2018; Dewaele \& MacIntyre, 2014; Dörnyei et al., 2015; Gregersen et al., 2014; MacIntyre et al., 2016). Hiver et al. (2021a, b) suggest that investigating and measuring the dynamics of emotions or emotional engagement as part of learner engagement (see Hiver et al., 2021c; Larsen-Freeman \& Cameron, 2008) is one of the potential ways forward to advance the current understanding of the characteristics, especially its malleability, of learner engagement and its dynamic relationship to other constructs as well as L2 learning (also see Sang \& Hiver, 
Dao, P. \& Sato, M. (2021, in press). Exploring fluctuations in the relationship between learners'5 positive emotional engagement and their interactional behaviours. Language Teaching Research, accepted on 17 August 2021

2021). However, little research to date has addressed the dynamic nature of learners' emotional engagement in relation to task-based performance.

Recent L2 task-based research has shown that learners' emotional engagement or affective responses during L2 task-based interaction affected their interactional behaviours (Author2, XXXX; Aubrey, 2017; Lambert et al., 2017; Nakamura et al., 2020; Phung, 2017; Phung et al., 2021; Qiu \& Lo, 2017). However, in these studies, learners' emotional engagement was measured only once during an entire task-based interaction (cf. Oga-Baldwin \& Fryer, 2021). Thus, little is known whether learners' emotional engagement changes over the course of task performance. Given the possible dynamic nature of emotional engagement, the relationship between learners' emotional engagement and their interactional behaviours, as observed in previous research (see Dörnyei et al., 2015, Mercer, 2019; Sulis \& Philp, 2021), might also change during the interaction. To examine such a relationship between learners' emotional engagement and task-based interaction, the current study focused on the characteristics of learners' emotional engagement. Specifically, it examined whether emotional engagement fluctuates over a course of a task-based interaction, and if so, whether these possible changes are associated with learners' interactional behaviours. With the focus on learners' emotional engagement at the level of a language learning task and following previous research that has operationalised the construct of learners' emotional engagement (see Early \& Marshall, 2008; Philp \& Duchesne, 2016; Phung et al., 2021, Skinner et al., 2009), emotional engagement in the current study was operationalised as learners' affective states emerging during task-based interaction. We hypothesized that learners' emotional states could derive from their experience 
Dao, P. \& Sato, M. (2021, in press). Exploring fluctuations in the relationship between learners'6 positive emotional engagement and their interactional behaviours. Language Teaching Research, accepted on 17 August 2021

during task-based interaction, on the one hand. On the other hand, their emotional states could affect their task-based performance.

\section{Literature Review}

\section{Emotions and Second Language Learning}

One type of learners' emotions that has attracted much attention in early L2 research is anxiety, which is defined as "a distinct complex of self-perceptions, beliefs, feelings and behaviours related to classroom learning arising from the uniqueness of the language learning process" (Horwitz et al., 1986, p. 128). This body of research attempted to investigate different individual, social, cognitive, and contextual factors that relate to L2 anxiety (Boudreau et al., 2018; Horwitz, 2010). However, a focus on negative emotions, such as L2 anxiety, has arguably not provided a full picture of a wide range of emotions that learners experience during the process of learning an L2 (Dörnyei \& Ryan, 2015).

Recently, in the field of positive psychology (MacIntyre et al., 2019; MacIntyre \& Mercer, 2014; also see Fredricks et al., 2019, Fredrickson, 2013), there have been calls for investigating the role of emotions in the learning of different contents. One of the central arguments of positive psychology is that empirical studies should broaden their perspectives, by investigating positive emotions which enable people to thrive and flourish, instead of focusing on negative emotions related to abnormalities, problems, and mental issues (Csikszentmihalyi \& Nakamura, 2011; Hefferon et al., 2017; Seligman, 2011; Seligman \& Csikszentmihalyi, 2000; Snyder et al., 2011). Applying positive psychology into the field of L2 learning, MacIntyre and Gregersen (2012, 2014), Gregersen et al. (2016), and MacIntyre et al. (2019) outlined a number of beneficial effects of positive emotions on learning an L2 (also see Gabrys-Barker \& Gałajda, 
Dao, P. \& Sato, M. (2021, in press). Exploring fluctuations in the relationship between learners 7 positive emotional engagement and their interactional behaviours. Language Teaching Research, accepted on 17 August 2021

2016; Strambi \& Rubino, 2017). For example, experiencing positive emotions is likely to (a) enhance learners' ability to pay attention to different aspects of the learning environment, (b) boost their awareness of language input and collaborative learning, (c) cancel out negative emotions that hinder their intake of language input and/or induce them to adopt a narrow focus in learning, (d) build up and enhance their long-term resiliency over the course of L2 learning (see MacIntyre \& Gregersen, 2012; MacIntyre et al., 2016), and (e) enable learners to co-construct a positive social cohesion with their peers (Author2, XXXX; Storch, 2002; Watanabe \& Swain, 2007).

Given the potential benefits of positive emotions, L2 research has started exploring the nature of and relationship between different dimensions of positive emotions in addition to negative ones, and their associations with a wide range of learner-internal and -external factors (see Gabrys-Barker \& Gałajda, 2016; MacIntyre et al., 2016; MacIntyre \& Gregersen, 2014; Strambi \& Rubino, 2017). This body of research has evidenced a wide range of positive emotions that learners experience and their impact on learning an L2 (e.g., lexical recall in Lambert et al., 2021). For instance, in the context of task-based interaction and the classroom, learners could experience positive emotions such as enjoyment (Ibrahim, 2016) and feelings of becoming interested in an interaction (see Renninger \& Hidi, 2016; Rotgans, \& Schmidt, 2017), as opposed to anxiety (Boudreau et al., 2018; Phung et al., 2021). Notably, these two types of emotions (negative versus positive) do not always form the two ends of a continuum. Rather, they could fluctuate and exist alongside each other (Phung et al., 2021), and at another time, one may emerge in the absence of the other (Dewaele \& Dewaele, 2017; Dewaele \& MacIntyre, 2014; MacIntyre \& Gregersen, 2012). The fluctuation of emotions during a lesson, a course, a 
Dao, P. \& Sato, M. (2021, in press). Exploring fluctuations in the relationship between learners 8 positive emotional engagement and their interactional behaviours. Language Teaching Research, accepted on 17 August 2021

semester, or years of study has been documented in a few studies (see Boudreau et al., 2018; Oga-Baldwin \& Fryer, 2021); however, little is known whether learners' emotions fluctuate over the course of a task-based interaction.

\section{Multifaceted and Dynamic Nature of Emotional Engagement}

In educational psychology, emotional engagement has been conceptualized as learners' affective reactions in the classroom and/or feelings of belonging and connection to school and a community at large, which features multidimensional and dynamic characteristics (Fredricks et al., 2004; Fredricks et al., 2019; Skinner \& Pitzer, 2012). Emotional engagement could encompass a wide range of components such as interest, enjoyment, happiness, enthusiasm, sadness, boredom, frustration, and anxiety (Fredricks et al., 2004; Philp \& Duchesne, 2016 Skinner et al., 2009). Within the context of the language classroom, Skinner et al. (2009) perceived learners' interest, enjoyment, and enthusiasm as key positive dimensions of learners' emotional engagement, whereas its negative dimensions include anxiety, frustration, and boredom. With regard to its dynamic characteristics, Kuppens and Verduyn (2017) argued that emotions reflect four principles of dynamics, including: (a) principle of contingency (i.e., emotions being contingent on both internal and external factors); (b) principle of inertia (i.e., at times emotions display resistance to change); (c) principle of regulation (i.e., emotions continuously regulate or change to fit optimally into an existing situation); and (d) principle of interaction (i.e., emotions interact predictably and unpredictably with other social and contextual factors). Thus, it is necessary to capture the changes in learners' emotional engagement since they are fluid, fleeting, and fluctuating, "sometimes appearing and disappearing within a short time frame" (Rotgans \& Schmidt, 2017, p. 5). 
Dao, P. \& Sato, M. (2021, in press). Exploring fluctuations in the relationship between learners 9 positive emotional engagement and their interactional behaviours. Language Teaching Research, accepted on 17 August 2021

In the field of L2 acquisition, the construct of emotional engagement has been conceptualised and defined differently depending on the research purpose (see Hiver et al., $2021 b$, for a recent review). For instance, drawing on research about student engagement in the field of educational psychology and the general learning sciences, Philp and Duchesne (2016) discuss emotional engagement as learners' affective involvement in a task, which is a subcomponent of task engagement alongside others such as cognitive engagement (i.e., sustained attention and mental attempts), social engagement (i.e., social affiliation and mutuality), and behavioural engagement (i.e., on-task participation). Emotional engagement then could be manifested in both positive dimensions such as interest and enjoyment and negative dimensions such as boredom and frustration (also see Early \& Marshall, 2008).

Svalberg $(2009,2017)$ perceives affective engagement as learners' (a) state of positive, purposeful, willing and autonomous orientation towards partners and the language, and/or (b) process of willingness to interact with the language and/or the interlocutor. Drawing on Svalberg's framework of engagement with language, Baralt et al. (2016) consider learners' affective engagement as learners' willingness to engage, purposefulness, and autonomy. Indicators of affective engagement could include learners' eagerness or withdrawal, degree of focus on task or boredom, and feelings of dependence on or independence of partners. Within the context of task performance, Phung et al. (2021) and Nakamura et al. (2020) operationalise affective engagement as consisting of learners' negative and positive emotions (i.e., enjoyment and anxiety) and their perceptions of their own task performance (i.e., focus and freedom of expression). 
Dao, P. \& Sato, M. (2021, in press). Exploring fluctuations in the relationship between learners0 positive emotional engagement and their interactional behaviours. Language Teaching Research, accepted on 17 August 2021

The current conceptualisations overall appear to converge on considering emotional engagement as (a) manifesting two key dimensions: positivity (e.g., learners' feelings of enjoyment and interest in the topic or the task being carried out) and negativity (e.g., feelings of anxious and/or disconnected with peers (also see Mercer, 2019), and (b) showing similar indicators such as interest, enjoyment, and anxiety. Following the existing conceptualisations of emotional engagement (Early \& Marshall, 2008; Nakamura et al., 2020; Philp \& Duchesne, 2016; Phung et al., 2021; Skinner et al., 2009) and tailoring to the current study's focus on learners' engagement at the level of a language learning task (Platt \& Brooks, 2002), we considered learners' emotional engagement in a task as featuring both positive (i.e., interest and enjoyment) and negative feelings (i.e., anxiety). In the current study, emotional engagement was originally operationalised as consisting of three main indicators: enjoyment, interest, and anxiety. However, the exploratory factor analyses (EFA), presented later in the Methods section, indicated that anxiety did not load highly on the latent variable of emotional engagement and was thus excluded. Consequently, the construct included in the final analyses resulted in positive emotional engagement that consists of two dimensions: enjoyment and interest.

\section{Enjoyment and Interest}

Enjoyment is a psychological state which can be perceived as one of the dimensions of flow, i.e., a state of intense involvement and heightened emotional intensity in tasks (Csikszentmihalyi \& Csikszentmihalyi, 1990) (see Aubrey, 2017; Egbert, 2003). Recently, there has been an increased emphasis on the important role of enjoyment in task performance and L2 learning. A number of studies have investigated learners' enjoyment, specifically foreign language enjoyment in task-based performance and/or L2 learning (e.g., Dewaele \& MacIntyre, 
Dao, P. \& Sato, M. (2021, in press). Exploring fluctuations in the relationship between learners'1 positive emotional engagement and their interactional behaviours. Language Teaching Research, accepted on 17 August 2021

2014, 2019) as well as its dynamic nature (Dewaele \& Dewaele, 2017, 2020). Overall, this research shows that foreign language enjoyment has dynamic characteristics and can be affected by multiple factors, such as individual learner and teacher variables (Dewaele et al., 2018, 2019), the L2 learning context (Dewaele et al., 2019), the L2 experiences (Ibrahim, 2016), and the nature of a task (Phung et al., 2021). However, this body of research has largely focused on learners' overall enjoyment during their process or journey of learning an L2 without specifically measuring it at the level of a task-based interaction. In addition, foreign language enjoyment research to date has mainly captured the fluctuation of learners' engagement over several lessons, a semester, and years, but little is known whether enjoyment fluctuates during the course of a task-based interaction. Documenting changes in a shorter time period is important not only to advance our theoretical understanding of emotional engagement but also to ensure the pedagogical value of task-based teaching.

Similar to the construct of enjoyment, interest has also gained attention in L2 research. Interest can refer to "deep and passionate engagement" with specific content, persons, situations and/or environments, which generally "includes positive feelings and desires to explore things that has personal meaning and values" (Ainley, 2017, p. 3-4). Interest can be classified into two types: situational interest (i.e., interest as an in-the-moment experience) and personal interest (i.e., interest as a more enduring personal characteristic). One important feature of interest that has been widely acknowledged and emphasized by scholars in the educational domain (see O'Keefe et al., 2017) is that interest, especially situational interest, is dynamic and bound to the immediate situation (Alexander, 2004). Interest is also closely related to the positive affective nature of learners' involvement in a learning activity or task (Early \& Marshall, 2008; Philp \& 
Dao, P. \& Sato, M. (2021, in press). Exploring fluctuations in the relationship between learners 2 positive emotional engagement and their interactional behaviours. Language Teaching Research, accepted on 17 August 2021

Duchesne, 2016; Skinner et al., 2009). To this end, little L2 research has investigated its dynamic nature and its relationship with learners' interactional behaviours during task performance.

\section{Emotional Engagement and Learners' Behaviours}

To date, a few L2 studies that follow the cognitive-interactionist approach have explored the relationship between learners' emotional engagement and their interactional behaviours. Those studies showed, for example, that learners reported greater enjoyment and anxiety in tasks with less constrained choices, as compared to those with greater constrained choices (Nakamura et al., 2020; Phung et al., 2021). Learners may demonstrate more positive affective responses when tasks featured familiar topics (Qiu \& Lo, 2017). Additionally, learners' flow was found to be correlated with turn-taking behaviours (Aubrey, 2017). Furthermore, learning environment elements, modes of interaction, and interlocutors were also reported as variables that either increased or decreased the degree of learners' enjoyment in the classroom tasks (Baralt et al., 2016; Carver et al., 2021; Sulis \& Philp, 2021). Notably, although high levels of engagement are crucial to the successful completion of a task and L2 learning, some studies suggest that different levels of engagement might result in different interactional behaviours. For example, learners with high levels of engagement tended to focus on fluency and accuracy aspects of language use, whereas those with low levels of engagement were more likely to focus on experimenting with new language, thus producing more syntactically complex language during task performance (Lambert \& Zhang, 2019). This shows a possible trade-off effect between learners' levels of engagement and linguistic foci during task-based performance.

Although these studies evidenced certain relationships between learners' emotional engagement and their interactional behaviours, and identified factors affecting learners' 
Dao, P. \& Sato, M. (2021, in press). Exploring fluctuations in the relationship between learners 3 positive emotional engagement and their interactional behaviours. Language Teaching Research, accepted on 17 August 2021

emotional engagement, they largely measured learners' emotional engagement once, either before or after task interaction. As mentioned above, learners' emotional engagement can be dynamic and fluctuate over different timeframes. It is, therefore, important to examine possible fluctuations in learners' emotional engagement over a short time frame and investigate whether these fluctuations are associated with their interactional behaviours, or vice versa.

\section{The Current Study}

The present study focused on exploring issues that have been rarely addressed in previous L2 interaction research. First, investigating the dynamic nature of learners' emotional engagement in L2 task-based interaction represents a shift in research from treating it as a traitlike, unchanged construct to a dynamic construct, which follows new insights informed by the complex dynamic systems theory (Hiver et al., 2021c; Larsen-Freeman \& Cameron, 2008). When L2 learners' emotional engagement is considered as state-like and susceptible to change, it is pivotal that the measurement of this construct should be carried out multiple times over a timeframe. Second, to understand the impact of emotions on L2 learning, it is necessary to investigate how learners' emotional engagement in a task-based interaction relates to their behaviours that are perceived as conducive to L2 learning, and whether these relationships may change over the course of a task-based interaction. Third, following the increased recognition of the role of positive emotions in L2 learning informed by positive psychology, the current study specifically explored learners' positive emotional engagement which includes enjoyment and interest. Two research questions (RQ) were then formulated.

RQ1: How does learners' emotional engagement fluctuate over the course of a task-based interaction? 
Dao, P. \& Sato, M. (2021, in press). Exploring fluctuations in the relationship between learners'4 positive emotional engagement and their interactional behaviours. Language Teaching Research, accepted on 17 August 2021

RQ2: How are learners' levels of emotional engagement associated with their interactional behaviours?

\section{Method}

\section{Participants and the Context}

Participants were 74 Vietnamese EFL learners (38 females and 36 males), recruited from five English as a Foreign Language (EFL) classes at two public universities in the South of Vietnam. They ranged in age from 18 to 24 years old $(M=20.28, S D=1.13)$. Their language proficiency was assessed by a TOEFL paper-based test administered prior to the data collection. The test results showed a mean score of $449.89(S D=48.79)$, equivalent to the late A2 level or the early B1 level on the Common European Framework of Reference (CEFR). Participants reported that they had learned English at schools for between eight and 11 years, with none having studied in an English-speaking country. At the time of the data collection, they were undergraduate students majoring in different disciplines (e.g., biotechnology, computer science, primary education, business, and English education). Despite differences in their disciplines, they were all enrolled in a communicative English course as part of their university degree program.

It should be noted that apart from the convenience reasons, another main reason for recruiting this group of participants was that they were typical of L2 learners in this EFL context. That is, they all had continuous exposure to English language teaching that focused on developing grammatical knowledge during their compulsory education at primary, secondary, and high schools. The participants reported that their English classes, prior to their universitylevel classes, primarily revolved around grammar exercises and reading comprehension. Unlike 
Dao, P. \& Sato, M. (2021, in press). Exploring fluctuations in the relationship between learners'5 positive emotional engagement and their interactional behaviours. Language Teaching Research, accepted on 17 August 2021

their previous education, however, the participants were required to take a communicative English course as part of their university degree program. This communicative English course differed significantly from the English classes at their primary, secondary, and high schools because classroom activities were primarily designed to develop their communicative skills. For instance, the participants were regularly involved in pair/group work activities and communicative tasks that were similar to the task used in the current study. Since the data collection occurred at the beginning of their English course in their first semester of their first academic year, involvement in these communicative pair/group work activities was considered as a relatively new experience to this group of learners. Given this, findings from this study about their emotional engagement and interactional behaviours would provide insights into the practice of English learning and teaching in the participants' context and thus they could be more applicable to other EFL contexts that share comparable characteristics.

\section{Design}

This study investigated the nature of emotional engagement and its relationship with interactional behaviours. To explore the nature of emotional engagement, a questionnaire measuring learners' level of emotional engagement was administered three times after every five-minute interval of a 15-minute interaction. A communicative picture-sequencing task taken from previous research (Dao \& McDonough, 2018) was used, in which learners discussed 10 pictures in a random order to form a meaningful story (see Appendix for task instructions and pictures). The repeated delivery of the questionnaire was guided by the principle of Experience Sampling Method (ESM) (see Csikszentmihalyi, 2014; Hektner et al., 2007; Hiver \& Al-Hoorie, 2019; Zhou et al., 2021) whose primary purpose is to capture the learners' self-reported 
Dao, P. \& Sato, M. (2021, in press). Exploring fluctuations in the relationship between learners'6 positive emotional engagement and their interactional behaviours. Language Teaching Research, accepted on 17 August 2021

experience at regular intervals as it emerges and/or is directly perceived from one moment to the next. Despite being an indirect measure (Fredricks \& McColskey, 2012), this self-report method allowed for tracking the fluctuation of learners' emotional engagement simultaneously over the course of the interaction.

Learners' interactional behaviours were measured by the quantity of language production (i.e., the number of words and turns), attention to form (i.e., language-related episodes: LREs), and the degree of collaboration. To investigate the relationship between the learners' emotional engagement and their interactional behaviours, correlations were performed between emotional engagement scores and those of four measures of interactional behaviours: (a) the amount of L2 production, i.e., the number of words and turns, (b) learners' attention to form operationalized as LREs, and (c) the degree of collaboration. Importantly, learners' emotional engagement could be reciprocally influenced (i.e., affecting and being affected) by a variety of individual and contextual factors, such as the interlocutor, the learners' proficiency, and perceptions of partners, and the task itself (Author1, XXXX; Author2, XXXX; Mystkowska-Wiertelak, 2020; Skinner et al., 2009; Sulis \& Philp, 2021). Consequently, a predictive model (e.g., regression modelling) was avoided as it presupposes a cause-and-effect relationship.

\section{Procedure}

The data were collected during two sessions (180 minutes in total) in a lab-based setting. In the first 120-minute session, the researcher (the first author) first introduced the research project and then collected consents from the participants. Those participants who agreed to participate in the project completed a TOEFL paper-based test. In a 60-minute session, scheduled a day after the first session, a research assistant randomly paired the learners, provided task 
Dao, P. \& Sato, M. (2021, in press). Exploring fluctuations in the relationship between learner\$7 positive emotional engagement and their interactional behaviours. Language Teaching Research, accepted on 17 August 2021

instructions, and answered clarification questions. The participants then carried out the task in dyads for 15 minutes. At the $5^{\text {th }}$ and $10^{\text {th }}$ minute points in the task, participants paused the interaction and completed the emotional engagement questionnaire. At the end of the task, they answered the questionnaire one last time. Their interactions were audio recorded.

\section{The Emotional Engagement Questionnaire}

We operationalised learners' emotional engagement as an affective state that includes enjoyment, interest, and anxiety. The three constructs were then used to create a three itemquestionnaire to measure learners' emotional engagement. Although a short questionnaire has its limitations, a three-item questionnaire was argued to be theoretically sufficiently sound (Gogol et al., 2014; see below for the questionnaire's validity). For the current study, the short three-item questionnaire was deemed necessary in order to maintain the continuation of learners' communicative interaction and help them resume the interaction quickly after answering the questionnaire. The emotional engagement questionnaire asked the learners to indicate their levels of anxiety, interest, and enjoyment on a 10-point Likert scale by responding to three items: (1) How much have you been interested in the interaction?; (2) How much have you been anxious during the interaction?; (3) How much have you enjoyed the interaction? The wording of the questions was based on a content perspective (Dörnyei \& Taguchi, 2010; Schaeffer \& Presser, 2003) in which expressions most directly related to the constructs such as interest (i.e., " $b e$ interested in"), enjoyment (i.e., "enjoy"), and anxiety (i.e., "be anxious") were chosen. Each question was constructed with the aim of using words that all participants as laypersons could understand easily, and that best represents the essence of the constructs. The questionnaire was administered in the participants' first language (Vietnamese). 
Dao, P. \& Sato, M. (2021, in press). Exploring fluctuations in the relationship between learner\$ 8 positive emotional engagement and their interactional behaviours. Language Teaching Research, accepted on 17 August 2021

To examine whether the three questionnaire items measuring learners' levels of enjoyment, interest, and anxiety reflect the latent variable - emotional engagement, we ran an EFA to check the three-item questionnaire's validity. Data collected from all three intervals were combined, and averaged scores of learners' emotional engagement were calculated and entered into an EFA, with the extraction method being principal component analysis. The results showed that the Kaiser-Meyer-Olkin (KMO) value, a measure of sampling adequacy, was at an acceptable level of .56, indicating that the patterns of correlations were relatively compact, and so the factor analysis could yield distinct and reliable factors. Bartlett's test of sphericity was significant $(p<.001)$. Based on Kaiser's criterion for communalities after extraction being greater than .70 and Eigenvalues being greater than 1, one factor was extracted from the analysis, which was subsequently operationalized as a latent variable of emotional engagement. The factor accounted for $53.54 \%$ of the total variance.

Notably, only two items were loaded on this latent variable: enjoyment (.88) and interest (.86). Anxiety's loading was low (-.31), and subsequently excluded from the analyses. Since only one factor was extracted, the solution was not rotated in the factor analysis. In the end, the construct of emotional engagement in the current study included two positive aspects of interest and enjoyment and henceforth called positive emotional engagement. To check the reliability of this two-item questionnaire, Spearman-Brown coefficients were calculated. High internal consistencies were observed at the three data collection points: .83 (Interval 1); .86 (Interval 2); and .88 (Interval 3).

\section{Interaction Data Analysis}


Dao, P. \& Sato, M. (2021, in press). Exploring fluctuations in the relationship between learnerd 9 positive emotional engagement and their interactional behaviours. Language Teaching Research, accepted on 17 August 2021

Learners' audio-recorded interactions were first coded for (a) the number of words, (b) the number of turns, and (c) the number of LREs (continuous variables). The scores for each coding category were calculated three times (i.e., three scores in total for each coding category as corresponding to the three 5-minute intervals of an interaction). To count the number of words and turns, we first excluded fillers (e.g., yeah, uh, uhm) and then used a word count and numbering Microsoft functions to calculate two scores for how many words and turns per interaction each learner produced, respectively. In Excerpt 1 below, Learner P1 produced 11 words and three turns, whereas Learner P2 uttered 18 words and three turns.

Excerpt 1. Language-related episode (LREs)

1. P1: Maybe we put it here how about you?

2. $\mathrm{P} 2$ : The second picture there is there are kid

3. P1: Kid-Children?

4. P2: Children

5. P1: Children yeah

6. P2: okay and the little girl is playing doll and...

To code LREs, we followed Swain and Lapkin's (1998) definition of LREs as any talk segments where the learners timed out or switched to discuss language form during the meaningbased interaction. Excerpt 1 above consisted of two LREs: self-correction (an existential there error, line 2) and other correction (a lexical choice between kid and children, lines 2 to 5). Specifically, in Excerpt 1, the learners were describing a picture in which children were playing in a countryside. The first LRE was in Line 2 in which Learner P2 self-corrects an existential there error from 'there is' to 'there are'. The second LRE was a segment (Lines 2-5) in which 
Dao, P. \& Sato, M. (2021, in press). Exploring fluctuations in the relationship between learner\&0 positive emotional engagement and their interactional behaviours. Language Teaching Research, accepted on 17 August 2021

Learner P1 corrects his partner P2's utterance of '[there are kid' as '[there are $]$ children'. For this exchange, Learner P2 was given a score of 2 (i.e., two instances of LREs) since he was involved in two LREs, whereas Learner P1 received a score of 1 (i.e., one instance of LRE).

Audio-recorded interactions were also coded for learners' degree of collaboration (nominal variable). We followed Storch's (2002) dyadic framework of interaction, which consists of four categories: collaborative, expert/novice, dominant/dominant, and dominant/passive. Apart from these categories, a 'parallel' category was added to represent the 'solo-versus-solo' interaction (Galaczi, 2008). That is, neither of the learners showed dominance, as in the dominant/dominant category. Instead, they equally initiated and developed ideas in parallel during the interaction (high equality) but showed little reflection and engagement with each other's ideas (low mutuality). It should be noted that Storch's and Galaczi's frameworks focused on the social relationship formed by two (or more than two) learners in an interaction. In the current study, we first identified the social relationship of a pair; for example, dominant/passive pattern. Based on the identified pattern, we coded each learner's degree of collaboration by assigning the two learners either as 'dominant' or 'passive'. For collaborative pairs, both learners' degree of collaboration was coded 'collaborative'. Each learner's degree of collaboration was assessed three times in total (three 5-minute intervals). For statistical purposes, following previous research (Dao \& McDonough, 2017), the degrees of collaboration were then grouped into two broad types: high mutuality (collaborative, expert, or novice) and low mutuality (dominant, parallel, or passive). These two categories were similar to Author2's (XXXX) categorization of collaboration: collaborative versus non-collaborative. 
Dao, P. \& Sato, M. (2021, in press). Exploring fluctuations in the relationship between learner\&'1 positive emotional engagement and their interactional behaviours. Language Teaching Research, accepted on 17 August 2021

For the coding reliability, the first author coded the entire dataset and trained a research assistant who independently coded $20 \%$ of the data. Pearson correlations for the frequencies of LREs identified by the two coders was .92 and Kappa for the degree of collaboration was .84.

\section{Results}

The first research question asked whether learners' positive emotional engagement fluctuates during the interaction. Descriptive statistics of the positive emotional engagement scores (i.e., averaged scores of interest and enjoyment) at three intervals showed that 61 out of 74 learners $(82.43 \%)$ reported changes in their positive emotional engagement levels over 15 minutes of interaction. Table 1 summarises descriptive statistics for the positive emotional engagement and its sub-constructs.

Table 1

Learners' Positive Emotional Engagement in Interaction $(N=74)$

\begin{tabular}{lccccccccc}
\hline & \multicolumn{3}{c}{ Interval 1 } & \multicolumn{3}{c}{ Interval 2 } & \multicolumn{3}{c}{ Interval 3 } \\
\cline { 2 - 9 } & Enjoyment & Interest & EE & Enjoyment & Interest & EE & Enjoyment & Interest & EE \\
\hline Mean & 7.09 & 6.89 & 6.99 & 7.39 & 7.35 & 7.37 & 7.61 & 7.58 & 7.59 \\
$S D$ & 1.70 & 1.82 & 1.62 & 1.71 & 1.63 & 1.56 & 1.79 & 1.70 & 1.65 \\
Min & 2 & 3 & 3 & 3 & 3 & 3 & 1 & 3 & 2 \\
Max & 10 & 10 & 10 & 10 & 10 & 10 & 10 & 10 & 10 \\
\hline
\end{tabular}

Note. $\mathrm{EE}=$ Emotional engagement (an averaged score of enjoyment and interest scores)

In Table 1, there were intra-individual variations in the learners' self-reported levels of positive emotional engagement across three intervals, as reflected in the ranges of min-max scores. The ANOVA detected significant differences between the three intervals: $F(2,72)=$ $12.07, p<0.01, \eta^{2}=.251$. The post hoc pair-wise analyses with Bonferroni corrections revealed 
Dao, P. \& Sato, M. (2021, in press). Exploring fluctuations in the relationship between learnerß2 positive emotional engagement and their interactional behaviours. Language Teaching Research, accepted on 17 August 2021

that there were significant differences between the first and the second intervals $(p=.006, d=$ .37) with a small effect size, and between the first and third intervals $(p<.001, d=.58)$ with a medium effect size. No significant difference was observed between the second and third intervals $(p=.064, d=.24)$.

The second research question asked whether positive emotional engagement is associated with learners' interactional behaviours. Descriptive statistics of four measures (i.e., words, turns, LREs, and the degree of collaboration) gauging learners' interactional behaviours at three intervals are presented in Tables 2 and 3 .

Table 2

Learners' Interactional Behaviours Measured by Number of Words Produced, Turns, and LREs $(N=74)$

\begin{tabular}{llccc}
\hline \multicolumn{1}{c}{} & Interval 1 & Interval 2 & Interval 3 \\
\hline Words & Mean & & & \\
& Standard deviation & 237.32 & 221.73 & 232.16 \\
& Min & 102.69 & 104.64 & 121.38 \\
& Max & 24 & 17 & 50 \\
Turns & Mean & 555 & 545 & 597 \\
& Standard deviation & 26.27 & 23.73 & 14.18 \\
& Min & 11.46 & 13.33 & 7 \\
& Max & 6 & 6 & 86
\end{tabular}


Dao, P. \& Sato, M. (2021, in press). Exploring fluctuations in the relationship between learner\&3 positive emotional engagement and their interactional behaviours. Language Teaching Research, accepted on 17 August 2021

\begin{tabular}{lccc} 
Standard deviation & 2.62 & 2.92 & 2.34 \\
Min & 0 & 0 & 0 \\
Max & 13 & 15 & 10 \\
\hline
\end{tabular}

As can be seen in Table 2, the amount of language production and LREs varied across the three intervals. At the first interval, learners produced a mean of 237.31 words and 26.27 turns, which decreased slightly to 221.73 words and 23.73 turns at the second interval, before increasing modestly to 232.16 words and 24.81 turns at the third interval. Meanwhile, the frequency of LREs decreased steadily from 3.58 at the first interval to 3.06 and 2.85 at the second and third intervals, respectively. Although descriptive results show differences in the number of words, turns, and LREs across three intervals, the results of Friedman tests revealed that these differences were not significant for Words: $\chi 2(2,74)=2.57, p=.28, d=.62,95 \% \mathrm{CIs}$ for mean differences between Intervals 1 and 2 [-12.34; 43.53], between Intervals 2 and 3 [50.29; 29.32], between Intervals 1 and 3 [-31.89; 42.21]. The Friedman test results also showed non-significant mean differences for Turns $\chi 2(2,74)=5.12, p=.07, d=1.46,95 \%$ CIs for mean differences between Intervals 1 and 2 [-.013; 5.09], between Intervals 2 and 3 [-5.37; 3.20], between Intervals 1 and 3 [-2.28; 5.19]. Similarly, non-significant results for LREs were also observed: $\chi 2(2,74)=5.13, p=.08, d=1.47,95 \%$ CIs for mean differences between Intervals 1 and $2[-3.83 ; 1.4]$, between Intervals 2 and $3[-.89 ; 1.33]$, between Intervals 1 and 3 [-.33; 1.79]. Notably, in Table 2, the standard deviations were quite large, indicating that there was variability among learners in terms of their interactional behaviours.

Table 3 
Dao, P. \& Sato, M. (2021, in press). Exploring fluctuations in the relationship between learner\&'4 positive emotional engagement and their interactional behaviours. Language Teaching Research, accepted on 17 August 2021

Learners’ Interactional Behaviours Measured by Degree of Collaboration

\begin{tabular}{lcccccc}
\hline & \multicolumn{2}{c}{ Interval 1} & \multicolumn{2}{c}{ Interval 2} & \multicolumn{2}{c}{ Interval 3 } \\
& $n$ & $\%$ & $n$ & $\%$ & $n$ & $\%$ \\
\hline High mutuality & 46 & 62.16 & 39 & 52.70 & 37 & 50.00 \\
Collaborative & 38 & 51.35 & 39 & 52.70 & 37 & 50.00 \\
Expert & 4 & 5.41 & 0 & 0 & 0 & 0 \\
Novice & 4 & 5.41 & 0 & 0 & 0 & 0 \\
Low mutuality & 28 & 37.84 & 35 & 47.30 & 37 & 50.00 \\
Parallel & 20 & 27.03 & 25 & 33.78 & 18 & 24.32 \\
Dominant & 7 & 9.46 & 6 & 8.11 & 10 & 13.51 \\
Passive & 1 & 1.35 & 4 & 5.41 & 9 & 12.17 \\
\hline
\end{tabular}

Learners' degrees of collaboration also changed across the three intervals (Table 3 ). The proportions of learners taking the roles of collaborative, expert, and novice roles which show high mutuality were at the highest $(62.16 \%)$ at Interval 1 but reduced at subsequent intervals, being at $52.70 \%$ (Interval 2) and 50\% (Interval 3). This corresponded to an increase in the low mutuality roles (i.e., parallel, dominant, passive) from $37.84 \%$ (Interval 1) to $47.30 \%$ (Interval 2) and 50\% (Interval 3). However, Cochran's $Q$ test showed that the differences in learners' degrees of collaboration were not significant across three intervals, $\chi^{2}(2,74)=2.63, p=.27, d=.38$.

To examine the relationship between learners' positive emotional engagement and their interactional behaviours, a series of correlations (i.e., Spearman and Point-biserial correlations) 
Dao, P. \& Sato, M. (2021, in press). Exploring fluctuations in the relationship between learner\&5 positive emotional engagement and their interactional behaviours. Language Teaching Research, accepted on 17 August 2021

were conducted on the scores of learners' emotional engagement and each measure of learners' interactional behaviours across three intervals. The results are presented in Table 4.

Table 4

Correlations between Positive Emotional Engagement and Learners' Interactional Behaviours

$\begin{array}{lll}\text { Emotional } & \text { Emotional } & \text { Emotional } \\ \text { engagement } & \text { engagement } & \text { engagement } \\ \text { (Interval 1) } & (\text { Interval 2) } & \text { (Interval 3) } \\ r_{S / p b}(p) & r_{S / p b}(p) & r_{S / p b}(p)\end{array}$

Interval 1

No. of words produced

\begin{tabular}{|c|c|c|}
\hline $.305^{* *}(.008)$ & $.276^{*}(.017)$ & $.228(.287)$ \\
\hline $.241^{*}(.039)$ & $.328^{* *}(.004)$ & $.264^{*}(.023)$ \\
\hline $.279^{*}(.016)$ & $.226(.053)$ & $.303^{* *}(.012)$ \\
\hline $.157(.181)$ & $.130(.270)$ & $.169(.150)$ \\
\hline
\end{tabular}

Interval 2

No. of words produced

$.148(.207)$

$.069(.560)$

$.125(.287)$

No. of turns

$.049(.676)$

$.094(.428)$

$.088(.455)$

Degree of collaboration

$.230 *(.049)$

$.209(.074)$

$.291 *(.012)$

No. of LREs

$.112(.344)$

$.141(.231)$

$.167(.150)$

Interval 3

No. of words produced

$.218(.062)$

$.296 *(.011)$

$.176(.135)$

No. of turns

$.180(.126)$

$.198(.090)$

$.219(.060)$

Degree of collaboration

$.004(.972)$

$.117(.319)$

$.016(.889)$ 
Dao, P. \& Sato, M. (2021, in press). Exploring fluctuations in the relationship between learner\&'6 positive emotional engagement and their interactional behaviours. Language Teaching Research, accepted on 17 August 2021

No. of LREs

$.049(.677)$

$.037(.755)$

$.037(.754)$

$* *=$ correlation is significant at the .01 level (2-tailed)

$*=$ correlation is significant at the .05 level (2-tailed

In terms of the relationship between learners' interactional behaviours and their positive emotional engagement reported at the end of the first interval, the results showed that learners' language production, $r_{s}=.305, p=.008$ (no. of words); $r_{s}=.241, p=.039$ (no. of turns) and degree of collaboration, $r_{p b}=.279, p=.016$ were positively correlated with their positive emotional engagement reported at the end of the first interval of the interaction. This indicates that after producing a high number of words and turns and showing a high degree of collaboration, the learners reported a high level of positive emotional engagement. However, the significant relationships disappeared in the second and third intervals: At the end of the second interval, $r_{s}=.069, p=.560$ (no. of words); $r_{s}=.094, p=.428$ (no. of turns); $r_{p b}=.209, p=.074$ (degree of collaboration); at the end of the third interval, $r_{s}=.176, p=.135$ (no. of words); $r_{s}$ $=.219, p=.060$ (no. of turns); $r_{p b}=.016, p=.889$ (degree of collaboration).

With regards to the relationship between learners' positive emotional engagement reported at the previous interval and their interactional behaviours in the subsequent interval, the results showed that after reporting a high level of positive emotional engagement at the $5^{\text {th }}$ minute (i.e., after Interval 1), the learners showed a higher degree of collaboration $\left(r_{p b}=.230, p\right.$ $=.049$ ) during Interval 2 . The emotional engagement scores at the $10^{\text {th }}$ minute (i.e., after Interval 2 ), were related to the number of words in the subsequent Interval $3\left(r_{s}=.296, p=.011\right)$. Finally, the results also showed that there were no observed significant correlations between the 
Dao, P. \& Sato, M. (2021, in press). Exploring fluctuations in the relationship between learner\&7 positive emotional engagement and their interactional behaviours. Language Teaching Research, accepted on 17 August 2021

learners' emotional engagement and their discussion of language form (i.e., LREs) across all three intervals.

\section{Discussion}

The first research question explored the nature of emotional engagement during a communicative task. The results showed that learners reported significant changes in their positive emotional engagement from the first interval to the second interval and to the third interval, but there were no significant changes from the second interval to the third interval of the interaction. Supporting previous research (e.g., Boudreau et al., 2018), these results suggest that learners' positive emotional engagement is susceptible to change even within a short communicative task.

In addition, the significant increase in learners' levels of positive emotional engagement from Interval 1 to subsequent intervals (Intervals 2 and 3) and the non-significant differences in learners' emotional engagement between Intervals 2 and 3 indicate that learners' positive emotional engagement took some time to stabilize over the course of the 15-minute task. One possible explanation is that when performing a relatively new type of communicative task which was introduced at the beginning of their English course in their first semester of their first academic year, learners might have been less emotionally engaged and more focused on language aspects in the beginning segment of their interaction. However, as they warmed up and proceeded to the next stages of the interaction, they might have become more comfortable, thus focusing more on social and interactive dimensions of their interactions. This therefore suggests a trade-off effect in learners' focus between on language features and social/interactive 
Dao, P. \& Sato, M. (2021, in press). Exploring fluctuations in the relationship between learner88 positive emotional engagement and their interactional behaviours. Language Teaching Research, accepted on 17 August 2021

dimensions of an interaction during the course of task completion (Lambert \& Zhang, 2019; see Ellis et al., 2020).

The second research question asked about the relationship between learners' emotional engagement and interactional behaviours. The results showed that positive emotional engagement was positively correlated with the amount of L2 production (i.e., no. words and turns). These results suggest that, on the one hand, the changes in learners' emotional engagement correspond to changes in learners' language production. On the other hand, the changes in the amount of language production might also lead to the changes in learners' positive emotional engagement. From the cognitive-interactionist perspective, language production during interaction affords learners opportunities to receive input, interactional feedback, and to modify output, all of which are considered facilitative and central to L2 learning (Gass \& Mackey, 2015). Given the relationship between language production and L2 learning, promoting learners' positive emotional engagement would be useful for increasing language production, thus creating interaction opportunities for facilitating L2 learning. Similarly, creating more opportunities for learners to produce language is more likely to result in increased positive emotional engagement, which in turn facilitates language production, thereby benefiting L2 learning. The results of the present study, therefore, emphasize a crucial role of positive emotions in promoting language production and L2 learning.

The results also showed that learners' emotional engagement was positively correlated with the degree of collaboration. These results indicate that when learners' positive emotional engagement during the interaction increased, their positive social relationships, as reflected in high mutuality or collaboration, correspondingly became stronger. Alternatively, when learners 
Dao, P. \& Sato, M. (2021, in press). Exploring fluctuations in the relationship between learneræ9 positive emotional engagement and their interactional behaviours. Language Teaching Research, accepted on 17 August 2021

showed a higher level of collaboration, they were more likely to experience a higher level of positive emotional engagement. Research using sociocultural theory suggests that maintaining learners' high collaboration or mutuality in interaction is important since it is considered as conducive to language learning opportunities (Storch, 2002; also see Author1, XXXX). Thus, promoting and maintaining learners' emotional engagement and a high degree of collaboration among learners are important because it would benefit learners' task performance in varied aspects such as collaborative L2 learning (Watanabe \& Swain, 2007).

Although learners' positive emotional engagement was observed to be positively correlated with the amount of L2 production and degree of collaboration, the results showed that it was not associated with learners' attention to form operationalized as LREs. The results indicate that experiencing positive emotions may not be related to the ways in which learners shift their attention to language form during their meaning-based L2 interaction. It is possible that positive emotions create conditions for learners to attend to other aspects of interaction (e.g., relationship with partners, task completion, and task contribution) rather than language form. This interpretation was supported by previous research findings showing that learners with high levels of engagement tend to focus on task content, social engagement with partners and interactive dimensions of their communication rather than attending to linguistic issues (Lambert \& Zhang, 2019; see Ellis et al., 2020).

The results also showed that that positive emotional engagement reported at the end of each interval was correlated only with learners' L2 production and degree of collaboration in the first interval, but not in the second and third intervals of the interaction. In addition, the relationships between learners' positive emotional engagement in the previous interval and their 
Dao, P. \& Sato, M. (2021, in press). Exploring fluctuations in the relationship between learner30 positive emotional engagement and their interactional behaviours. Language Teaching Research, accepted on 17 August 2021

behaviours in the subsequent interval as well as the relationship between learners' interactional behaviours in the previous interval and their positive emotional engagement in the subsequent interval were observed to vary (i.e., appeared, disappeared, and re-emerged) across three intervals. These results indicate that the relationship between learners' positive emotional engagement and their interactional behaviours was not stable and varied over the course of task completion. From the cognitive-interactionist perspective, the relationships among the focused variables could be, at some points, mediated by other factors such as internal individual differences (e.g., proficiency) and contextual and social factors (e.g., task implementation condition, perceptions of partners, and approach to tasks) (see Author2, XXXX for a review). It is possible that in the first interval these individual, contextual, and social factors were not present or salient enough; however, they might have become stronger in the second and third intervals after the learners experienced the interaction, thus possibly mediating the relationships between the focused variables. It should be noted that the possible mediating effects of these factors on the levels of learners' emotional engagement were not part of the study, which thus warrants more research in this area.

Notably, the results showed high variability in the scores for all measures of learners' interactional behaviours across three intervals as reflected in large standard deviations (see Table 2). The results suggest the potential role of individual differences in influencing learners' interactional behaviours. Recent research has suggested that having a closer look at individual differences apart from the general mean scores is important since it could help shed more light on understanding individual learners' interactional behaviours. On the one hand, the current study adds to this research by (a) conceptualizing emotional engagement as an individual 
Dao, P. \& Sato, M. (2021, in press). Exploring fluctuations in the relationship between learner3'1 positive emotional engagement and their interactional behaviours. Language Teaching Research, accepted on 17 August 2021

difference variable, and (b) using an associative design (i.e., correlations). On the other hand, given the fluctuations of emotional engagement found in the current dataset, we may consider emotional engagement as a situational, unpredictable variable, as opposed to a stable individual difference factor. The latter interpretation aligns with the view of the complex dynamic systems theory.

\section{Conclusion, Pedagogical Implications, and Limitations}

The current study examined the nature of learners' positive emotional engagement and its relationship with their interactional behaviours, in light of the amount of L2 production, attention to form, and the degree of collaboration. The results revealed that positive emotional engagement fluctuated across the three intervals within a 15-minute task-based interaction, and it was positively correlated with the amount of L2 production and the degree of collaboration; however, these relationships were not fixed and fluctuated during the interaction. In addition, the relationship between emotional engagement and LREs was not observed.

The study has some pedagogical implications. First, because learners' positive emotional engagement can change, teachers may be able to promote their learners' engagement even when they seem not interested in and/or enjoy the task at the beginning. Conversely, even if learners feel interested and show high enjoyment at the beginning of the interaction, it does not mean these positive emotions would remain over the course of the interaction. It is therefore important for teachers to observe and maintain learners' positive emotional engagement throughout the interaction for the sake of productive and effective interaction for L2 learning. Second, given that learners' emotional engagement was positively correlated with language production and collaboration, it is essential for teachers to find ways to promote learners' positive emotional 
Dao, P. \& Sato, M. (2021, in press). Exploring fluctuations in the relationship between learner32 positive emotional engagement and their interactional behaviours. Language Teaching Research, accepted on 17 August 2021

engagement. Some of the ways to promote their engagement (including emotional engagement) suggested in previous research include giving them opportunities to generate their own task content (Lambert et al., 2017, 2021; Nakamura, 2021), select their preferred tasks (Phung, 2017), practice interactional strategies (Dao, 2020); interact with peers of a different ethnolinguistic group (Aubrey, 2017; Phung, 2017), work with partners of different proficiency levels (Dao \& McDonough, 2017, 2018), use point cards to score and track their own performance for the sake of improving their performance (Stroud, 2017), and/or carry out tasks with a manipulation of task goals (Dao, 2019).

The study has some limitations. First, in order to maintain the flow of the conversation, a short emotional engagement questionnaire was used, which might not have captured fully the construct of emotional engagement. Based on the results of the EFA, only two items in the questionnaire that tapped into learners' emotional engagement were retained. Thus, future research may include other sub-constructs besides interest and enjoyment, in order to fully capture different dimensions of emotional engagement. Second, due to the focus on the nature of learners' positive emotional engagement, the current study did not document factors that might have caused the changes and moderated the relationship between learners' emotional engagement and their interactional behaviours (e.g., task features, interlocutor, allotted time, etc.). Third, there was high variability in scores of both learners' emotional engagement and interactional behaviours, which suggests that individual differences need to be considered and investigated in future research. In addition, the participants of this current study were relatively homogenous in terms of their scultural, sociolinguistic and learning backgrounds, which limits the generalizability of the results to other multilingual and multicultural contexts. 
Dao, P. \& Sato, M. (2021, in press). Exploring fluctuations in the relationship between learner33 positive emotional engagement and their interactional behaviours. Language Teaching Research, accepted on 17 August 2021 
Dao, P. \& Sato, M. (2021, in press). Exploring fluctuations in the relationship between learner3'4 positive emotional engagement and their interactional behaviours. Language Teaching Research, accepted on 17 August 2021

\section{References}

Ainley, M. (2017). Interest: Knows, unknowns and basic processes. In P. O’Keefe \& J. Karackiewicz (Eds), The science of interest (pp. 3-24). Cham: Springer.

Alexander, P. A. (2004). A model of domain learning: Reinterpreting expertise as a multidimensional, multistage process. In D. Y. Dai \& R. J. Sternberg (Eds.), Motivation, emotion and cognition: Integrative perspectives on intellectual functioning and development (pp. 273-298). Mahwah, NJ: Lawrence Erlbaum Associates.

Aubrey, S. (2017). Inter-cultural contact and flow in a task-based Japanese EFL classroom. Language Teaching Research, 21, 717-734. https://doi.org/10.1177/1362168816683563

Baralt, M., Gurzynski-Weiss, L., \& Kim, Y. (2016). Engagement with language: How examining learners' affective and social engagement explains successful learner-generated attention to form. In M. Sato \& S. Ballinger (Eds.), Peer interaction and second language learning. Pedagogical potential and research agenda (pp. 209-240). Amsterdam, The Netherlands: John Benjamins.

Boudreau, C., MacIntyre, P., \& Dewaele, J. M. (2018). Enjoyment and anxiety in second language communication: An idiodynamic approach. Studies in Second Language Learning and Teaching, 8, 149-170. https://doi.org/10.14746/ssllt.2018.8.1.7

Dao, P. (2020). Effect of interaction strategy instruction on learner engagement in peer interaction. System, 91, 102-244.

Dao, P. (2019). Effects of task goal orientation on learner engagement in task performance. International Review of Applied Linguistics in Language Teaching. Published online on 31 January 2019. 
Dao, P. \& Sato, M. (2021, in press). Exploring fluctuations in the relationship between learner3’5 positive emotional engagement and their interactional behaviours. Language Teaching Research, accepted on 17 August 2021

Dao, P., \& McDonough, K. (2018). Effect of proficiency on Vietnamese EFL learners' engagement in peer interaction. International Journal of Educational Research, 88, 60-72.

Dao, P., \& McDonough, K. (2017). The effect of task role on Vietnamese EFL learners' collaboration in mixed proficiency dyads. System, 65, 15-24.

Carver, C., Jung, D., \& Gurzynski-Weiss, L. (2021). Examining learner engagement in relationship to learning and communication mode. In P. Hiver, A. H. Al-Hoorie \& S. Mercer (Eds.) (2021), Student engagement in the language classroom (pp. 120-142). Clevedon: Multilingual Matters.

Csikszentmihalyi, M., \& Csikzentmihaly, M. (1990). Flow: The psychology of optimal experience. New York: Harper \& Row.

Csikszentmihalyi, M. (2014). Validity and reliability of the experience-sampling method. New York: Springer.

Csikszentmihalyi, M., \& Nakamura, J. (2011). Positive psychology: Where did it come from, where is it going? In M. K. Sheldon, T. B. Kashdan \& M. F. Steger (Eds.), Designing positive psychology: Taking stock and moving forward (pp. 3-8). New York: Oxford University Press.

Czimmermann, E., \& Piniel, K. (2016). Advanced language learners' experiences of flow in the Hungarian EFL classroom. In P. D. MacIntyre, T. Gregersen, \& S. Mercer (Eds.), Positive psychology in SLA (pp. 193-214). Bristol: Multilingual Matters.

Dewaele, J. M. (2019). The effect of classroom emotions, attitudes toward English, and teacher behavior on willingness to communicate among English foreign language learners. Journal 
Dao, P. \& Sato, M. (2021, in press). Exploring fluctuations in the relationship between learner36 positive emotional engagement and their interactional behaviours. Language Teaching Research, accepted on 17 August 2021

of Language and Social Psychology, 38, 523-535.

https://doi.org/10.1177/0261927X19864996

Dewaele, J. M., \& Dewaele, L. (2017). The dynamic interactions in foreign language classroom anxiety and foreign language enjoyment of pupils aged 12 to 18. A pseudo-longitudinal investigation. Journal of the European Second Language Association, 1, 12-22. https://doi.org/10.22599/jesla.6

Dewaele, J. M., \& Dewaele, L. (2020). Are foreign language learners' enjoyment and anxiety specific to the teacher? An investigation into the dynamics of learners' classroom emotions. Studies in Second Language Learning and Teaching, 10, 45-65. https://doi.org/10.14746/ss1lt.2020.10.1.3

Dewaele, J. M., Özdemir, C., Karci, D., Uysal, S., Özdemir, E. D., \& Balta, N. (2019). How distinctive is the foreign language enjoyment and foreign language classroom anxiety of Kazakh learners of Turkish? Applied Linguistics Review. Published online: 23 Jul 2019. https://doi.org/10.1515/applirev-2019-0021.

Dewaele, J. M., \& MacIntyre, P. D. (2014). The two faces of Janus? Anxiety and enjoyment in the foreign language classroom. Studies in Second Language Learning and Teaching, 4, 237-274. https://doi.org/10.14746/ssllt.2014.4.2.5

Dewaele, J. M., \& MacIntyre, P. D. (2016). Foreign language enjoyment and foreign language classroom anxiety: The right and left feet of FL learning? In P. D. MacIntyre, T. Gregersen, \& S. Mercer (Eds.), Positive Psychology in SLA (pp. 215-236). Bristol: Multilingual Matters. 
Dao, P. \& Sato, M. (2021, in press). Exploring fluctuations in the relationship between learner37 positive emotional engagement and their interactional behaviours. Language Teaching Research, accepted on 17 August 2021

Dewaele, J., M., \& MacIntyre, P. D. (2019). The predictive power of multicultural personality traits, learner and teacher variables on foreign language enjoyment and anxiety. In M. Sato \& S. Loewen (Eds.), Evidence-based second language pedagogy: A collection of instructed second language acquisition studies (pp. 263-286). London: Routledge.

Dewaele, J. M., Witney, J., Saito, K., \& Dewaele, L. (2018). Foreign language enjoyment and anxiety: The effect of teacher and learner variables. Language Teaching Research, 22, 676697. https://doi.org/10.1177/1362168817692161

Dörnyei, Z., MacIntyre, P. D., \& Henry, A. (Eds.). (2015). Motivational dynamics in language learning. Multilingual Matters.

Dörnyei, Z., \& Ryan, S. (2015). The psychology of the second language learner revisited. New York: Routledge.

Dörnyei, Z., \& Taguchi, T. (2010). Questionnaires in second language research: construction, administration and processing (2nd ed.). New York: Routledge.

Early, M., \& Marshall, S. (2008). Adolescent ESL students' interpretation and appreciation of literary texts: A case study of multimodality. Canadian Modern Language Review, 64, 377-397. https://doi.org/10.3138/cmlr.64.3.377

Egbert, J. (2003). A study of flow theory in the foreign language classroom. The Modern Language Journal, 87, 499-518.

Ellis, R., Skehan, P., Li, S., Shintani, N., \& Lambert, C. (2020). Task-based language teaching: Theory and practice. Cambridge University Press.

Fredricks, J.A., Reschly, A.L., \& Christenson, S.L. (Eds.) (2019). Handbook of student engagement interventions: Working with disengaged students. London: Academic Press. 
Dao, P. \& Sato, M. (2021, in press). Exploring fluctuations in the relationship between learner38 positive emotional engagement and their interactional behaviours. Language Teaching Research, accepted on 17 August 2021

Fredricks, J., Blumenfeld, P., \& Paris, A. (2004). School engagement: Potential of the concept, state of evidence. Review of Educational Research, 74, 59-105. https://doi.org/10.3102/00346543074001059

Fredricks, J. A., \& McColskey, W. (2012). The measurement of student engagement: A comparative analysis of various methods and student self-report instruments. In S. L. Christenson, A. L., Reschly \& C. Wylie (Eds), Handbook of research on student engagement (pp. 763-782). Springer, Boston, MA.

Fredrickson, B. L. (2013). Positive emotions broaden and build. In P. Devine \& A. Plant (Eds.), Advances in experimental social psychology (pp. 1-54). San Diego, CA: Academic Press.

Gass, S. M. \& A. Mackey (2015). Input, interaction, and output in second language acquisition. In B. VanPatten \& J. Williams (eds.), Theories in second language acquisition (2nd ed.). New York: Routledge,180-206.

Gabrýs-Barker, D., \& Gałajda, (Eds.). (2016). Positive psychology perspectives on foreign language learning and teaching. Berlin/Heidelberg: Springer.

Galaczi, E. D. (2008). Peer-peer interaction in a speaking test: The case of the first certificate in English examination. Language Assessment Quarterly, 5, 89-119. https://doi.org/10.1080/15434300801934702

Gogol, K., Brunner, M., Goetz, T., Martin, R., Ugen, S., Keller, U., Fischbach, A., \& Preckel, F. (2014). My questionnaire is too long! The assessments of motivational-affective constructs with three-item and single-item measures. Contemporary Educational Psychology, 39, 188-205. https://doi.org/10.1016/j.cedpsych.2014.04.002 
Dao, P. \& Sato, M. (2021, in press). Exploring fluctuations in the relationship between learner39 positive emotional engagement and their interactional behaviours. Language Teaching Research, accepted on 17 August 2021

Gregersen, T., MacIntyre, P. D., \& Meza, M. (2016). Positive psychology exercises build social capital for language learners: Preliminary evidence. In P. D. MacIntyre, T. Gregersen, \& S. Mercer (Eds.), Positive psychology in SLA (pp. 147-167). Bristol, UK: Multilingual Matters.

Gregersen, T., MacIntyre, P. D., \& Meza, M. D. (2014). The motion of emotion: Idiodynamic case studies of learners' foreign language anxiety. The Modern Language Journal, 98, 574-588. https://doi.org/10.1111/modl.12084

Hektner, J. M., Schmidt, J. A., \& Csikszentmihalyi, M. (2007). Experience sampling method: Measuring the quality of everyday life. Thousand Oaks, CA: SAGE.

Hefferon, K., Ashfield, A., Waters, L., \& Synard, J. (2017). Understanding optimal human functioning — The 'call for qual' in exploring human flourishing and well-being. Journal of Positive Psychology, 12, 211-219. https://doi.org/10.1080/17439760.2016.1225120

Hiver, P., \& Al-Hoorie, A. H. (2019). Research methods for complexity theory in applied linguistics. Multilingual Matters.

Hiver, P., Al-Hoorie, A.H., \& Mercer, S. (2021a). Student engagement in the language classroom. Multilingual Matters.

Hiver, P., Al-Hoorie, A. H., Vitta, J. P., \& Wu, J. (2021b). Engagement in language learning: A systematic review of 20 years of research methods and definitions. Language Teaching Research. Published online: March 24, 2021. https://doi.org/10.1177/13621688211001289

Hiver, P., Al-Hoorie, A.H., \& Larsen-Freeman, D. (2021c). Toward a transdisciplinary integration of research purposes and methods for complex dynamic systems theory: Beyond the quantitative-qualitative divide. International Review of Applied Linguistics in 
Dao, P. \& Sato, M. (2021, in press). Exploring fluctuations in the relationship between learner $\$ 0$ positive emotional engagement and their interactional behaviours. Language Teaching Research, accepted on 17 August 2021

Language Teaching. Published online: 15 February 2021. https://doi.org/10.1515/iral-20210022.

Horwitz, E., Horwitz, M., \& Cope, J. (1986). Foreign language classroom anxiety. The Modern Language Journal, 70, 125-132. https://doi.org/10.2307/327317

Horwitz, E. (2010). Foreign and second language anxiety. Language Teaching, 43, 154-167. https://doi.org/10.1017/S026144480999036X

Ibrahim, Z. (2016). Affect in directed motivational currents. In P. D. MacIntyre, T. Gregersen, S. Mercer (Eds), Positive psychology in SLA (pp. 258-281). Bristol: Multilingual Matters.

Kuppens, P., \& Verduyn, P. (2017). Emotion dynamics. Current Opinion in Psychology, 17, 2226. https://doi.org/10.1016/j.copsyc.2017.06.004

Lambert, C. (2017). Tasks affect and second language performance. Language Teaching Research, 21, 657-664. https://doi.org/10.1177/1362168817736644

Lambert, C., Gong, Q., \& Zhang, G. (2020). Learner-generated content and the lexical recall of beginning-level learners of Chinese as a foreign language. Language Teaching Research, Published on line on January 4, 2021

Lambert, C, Philp, J, \& Nakamura, S. (2017). Learner-generated content and engagement in second language task performance. Language Teaching Research, 21, 665-680. https://doi.org/10.1177/1362168816683559

Lambert, C., \& Zhang, G. (2019). Engagement in the use of English and Chinese as foreign languages: The role of learner-generated content in instructional task design. The Modern Language Journal, 103, 391-411. 
Dao, P. \& Sato, M. (2021, in press). Exploring fluctuations in the relationship between learner\&'1 positive emotional engagement and their interactional behaviours. Language Teaching Research, accepted on 17 August 2021

Larsen-Freeman, D. L., \& Cameron, L. (2008). Research methodology on language development from a complex systems perspective. The Modern Language Journal, 92, 200-213. https://doi.org/10.1111/j.1540-4781.2008.00714.x

MacIntyre, P. D. (2017). An overview of language anxiety research and trends in its development. In C. Gkonou, M. Daubney, \& J. M. Dewaele (Eds.), New insights into language anxiety: Theory, research and educational implications (pp. 1-24). Bristol, UK: Multilingual Matters.

MacIntyre, P. D., \& Gregersen, T. (2012). Emotions that facilitate language learning: The positive-broadening power of the imagination. Studies in Second Language Learning and Teaching, 2, 193-213. https://doi.org/10.14746/ssllt.2012.2.2.4

MacIntyre, P. D., \& Gregersen, T. (Eds.). (2014). Positive Psychology. Studies in Second Language Learning and Teaching, 4, 149-152. https://doi.org/10.14746/ssllt.2014.4.2.1

MacIntyre, P. D., Gregersen, T., \& Mercer, S. (Eds.). (2016). Positive psychology in SLA. Bristol: Multilingual Matters.

MacIntyre, P. D., Gregersen, T., \& Mercer, S. (2019). Setting an agenda for positive psychology in SLA: Theory, practice, and research. The Modern Language Journal, 103, 262-274. https://doi.org/10.1111/modl.12544

MacIntyre, P. D., \& Mercer, S. (2014). Introducing positive psychology to SLA. Studies in Second Language Learning and Teaching, 4, 153-172. http://doi. org/10.14746/ssllt.2014.4.2.2

Mercer, S. (2019). Language learner engagement: Setting the scene. In Gao, X. (Ed.), Second handbook of English language teaching (pp. 1-19). New York: Springer. 
Dao, P. \& Sato, M. (2021, in press). Exploring fluctuations in the relationship between learner\$2 positive emotional engagement and their interactional behaviours. Language Teaching Research, accepted on 17 August 2021

Mystkowska-Wiertelak, A. (2020). Teachers' accounts of learners' engagement and disaffection in the language classroom. The Language Learning Journal, 1-13. Published online: 26 Aug 2020. https://doi.org/10.1080/09571736.2020.1800067

Nakamura, S., Phung, L., \& Reinders, H. (2020). The effect of learner choice on L2 task engagement. Studies in Second Language Acquisition. Published online: 13 October 2020. https://doi.org/10.1017/S027226312000042X.

Oga-Baldwin, W. L. \& Fryer, L. K. (2021). Engagement growth in language learning classroom: A latent growth analysis of engagement in Japanese elementary schools. In P. Hiver, A. H. Al-Hoorie \& S. Mercer (Eds.), Student engagement in the language classroom (pp. 224240). Clevedon: Multilingual Matters.

O’Keefe, P. A., Horberg, E. J., \& Plante, I. (2017). The multifaceted role of interest in motivation and engagement. In P. O’Keefe, \& J. Karackiewicz (Eds), The science of interest (pp. 49-67). Cham: Springer.

Philp, J., \& Duchesne, S. (2016). Exploring engagement in tasks in the language classroom. Annual Review of Applied Linguistics, 36, 50-72. https://doi.org/10.1017/S0267190515000094

Phung, L. (2017). Task preference, affective response, and engagement in L2 use in a US university context. Language Teaching Research, 21, 751-766. https://doi.org/10.1177/1362168816683561

Phung, L., Nakamura, S. \& Reinders, H. (2021). The effect of choice on affective engagement: implications for task design. In P. Hiver, A. H. Al-Hoorie \& S. Mercer (Eds.), Student engagement in the language classroom (pp. 163-181). Clevedon: Multilingual Matters. 
Dao, P. \& Sato, M. (2021, in press). Exploring fluctuations in the relationship between learner\$3 positive emotional engagement and their interactional behaviours. Language Teaching Research, accepted on 17 August 2021

Platt, E., \& Brooks, F. B. (2002). Task engagement: A turning point in foreign language development. Language Learning, 52, 365-400. https://doi.org/10.1111/0023-8333.00187

Qiu, X., \& Lo, Y. Y. (2017). Content familiarity, task repetition and Chinese EFL learners' engagement in second language use. Language Teaching Research, 21, 681-698. https://doi.org/10.1177/1362168816684368

Renninger, K. A., \& Hidi, S. E. (2016). The power of interest for motivation and engagement. New York: Routledge.

Reschly, A.L., \& Christenson, S. L. (2012). Jingle, jangle, and conceptual haziness: Evolution and future directions of the engagement construct. In Christenson, S.L. Reschly, A.L. \& C. Wylie (Eds.), Handbook of research on student engagement (pp. 3-19). New York: Springer.

Rotgans, J. I., \& Schmidt, H. G. (2017). The role of interest in learning: knowledge acquisition at the intersection of situational and individual interest. In P. A. O'Keefe \& J. M. Harackiewicz (Eds.), The science of interest (pp. 69-98). Gewerbestreasse: Springer International.

Sang, Y. \& Hiver, P. (2021). Engagement and companion constructs in language learning: Conceptualizing learners' involvement in the L2 classroom. In P. Hiver, A. H. Al-Hoorie \& S. Mercer (Eds.), Student engagement in the language classroom (pp. 17-37). Clevedon: Multilingual Matters

Schaeffer, N. C., \& Presser, S. (2003). The science of asking questions. Annual Review of Sociology, 29, 65-88. https://doi.org/10.1146/annurev.soc.29.110702.110112 
Dao, P. \& Sato, M. (2021, in press). Exploring fluctuations in the relationship between learner\$'4 positive emotional engagement and their interactional behaviours. Language Teaching Research, accepted on 17 August 2021

Seligman, M. E. P. (2011). Flourish: A visionary new understanding of happiness and wellbeing. New York: Atria Books.

Seligman, M. E. P., \& Csikszentmihalyi, M. (2000). Positive psychology: An introduction. American Psychology, 55, 5-14. https://doi.org/10.1037/0003-066X.55.1.5

Skinner, E. A., Kindermann, T. A., \& Furrer, C. (2009). A motivational perspective on engagement and disaffection: Conceptualization and assessment of children's behavioral and emotional participation in academic activities in the classroom. Educational and Psychological Measurement, 69, 493-525. https://doi.org/10.1177/0013164408323233

Skinner, E. A., \& Pitzer, J. R. (2012). Developmental dynamics of engagement, coping, and everyday resilience. In S. L. Christenson, A. L. Reschly \& C. Wylie (Eds.), Handbook of research on student engagement (pp. 21-44). New York, NY: Springer.

Storch, N. (2002). Patterns of interaction in ESL pair work. Language Learning, 52, 119-158. https://doi.org/10.1111/1467-9922.00179

Strambi, A., \& Rubino, A. (Eds.). (2017). Flourishing in Italian: Positive Psychology approaches to the teaching and learning of Italian in Australia. Australian Review of Applied Linguistics, 40, 105-107. https://doi.org/10.1075/aral.40.2

Stroud, R. (2017). The impact of task performance scoring and tracking on second language engagement. System, 69, 121-132.

Sulis, G. \& Philp, J. (2021). Exploring connections between classroom environment and engagement in the foreign language classroom. In P. Hiver, A. H. Al-Hoorie \& S. Mercer (Eds.), Student engagement in the language classroom (pp. 101-129). Clevedon: Multilingual Matters. 
Dao, P. \& Sato, M. (2021, in press). Exploring fluctuations in the relationship between learner\$5 positive emotional engagement and their interactional behaviours. Language Teaching Research, accepted on 17 August 2021

Swain, M., \& Lapkin, S. (1998). Interaction and second language learning: Two adolescent French immersion students working together. The Modern Language Journal, 82, 320-337. https://doi.org/10.1111/j.1540-4781.1998.tb01209.x

Snyder, C. R., Lopez, S. J., \& Pedrotti, J. T. (2011). Positive psychology: The scientific and practical explorations of human strengths. Thousand Oaks, CA: Sage.

Svalberg, A. M. L. (2009). Engagement with language: Interrogating a construct. Language Awareness, 18, 242-258. https://doi.org/10.1080/09658410903197264

Svalberg, A. M. L. (2017). Researching language engagement: Current trends and future directions. Language Awareness, 27, 21-39.

https://doi.org/10.1080/09658416.2017.1406490

Teimouri, Y., Goetze, J., \& Plonsky, L. (2019). Second language anxiety and achievement: A meta-analysis. Studies in Second Language Acquisition, 41, 363-387. https://doi.org/10.1017/S0272263118000311

Watanabe, Y., \& Swain, M. (2007). Effects of proficiency differences and patterns of pair interaction on second language learning: Collaborative dialogue between adult ESL learners. Language Teaching Research, 11, 1-22.

https://doi.org/10.1177/136216880607074599

Zhou, S., Hiver, P., \& Al-Hoorie, A. H. (2021). Measuring L2 engagement: A review of issues and applications. In P. Hiver, A. H. Al-Hoorie \& S. Mercer (Eds.), Student engagement in the language classroom (pp. 75-100). Clevedon: Multilingual Matters. 
Dao, P. \& Sato, M. (2021, in press). Exploring fluctuations in the relationship between learner\$'6 positive emotional engagement and their interactional behaviours. Language Teaching Research, accepted on 17 August 2021

Picture-sequencing task: Instruction

- Task duration: 15 minutes

- Working with a partner

- Sequence the following pictures in an appropriate order to create a meaningful and interesting story of a person, ranging from childhood to adulthood

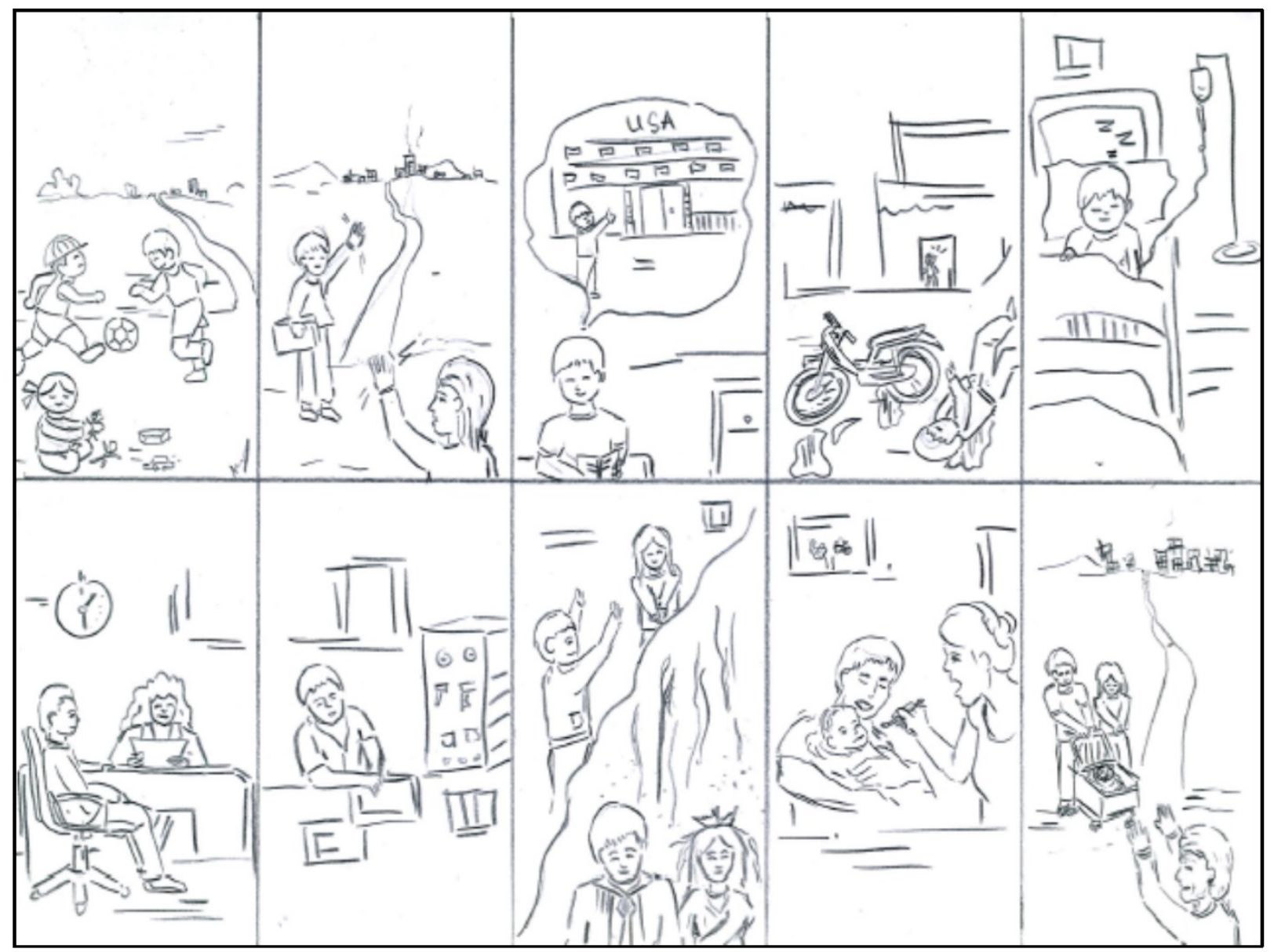

